\title{
ESPAÇO PLURAL \\ ZYGMUNT BAUMAN: \\ ENTREVISTA SOBRE A EDUCAÇÃO. \\ DESAFIOS PEDAGÓGICOS \\ E MODERNIDADE LÍQUIDA
}

\section{ALBA PORCHEDDU \\ Segunda parte da entrevista: \\ Os desafios da educação: aprender a caminhar sobre areias movediças}

Tradução: Neide Luzia de Rezende e Marcello Bulgarelli

Zygmunt Bauman (Polônia, 1925). Sociólogo, catedrático emérito de Sociologia nas Universidades de Leeds e Varsóvia, autor de diversos ensaios, entre os quais se encontram: Globalização: as consequências humanas (1999), Vida para consumo: a transformação das pessoas em mercadoria (2008), Em busca da política (2000), Modernidade líquida (200 I), Vidas desperdiçadas (2005). Seus trabalhos contribuíram para a edificação de um complexo e completo instrumental conceitual em torno da sociedade moderna. Embora seja frequentemente mencionado como um pensador "pós-moderno", seus livros não representam uma visão entusiasmada do pós-modernismo; aliás, ele se distancia da separação dicotômica modernidade versus pós-modernidade, argumentando que ambas as configurações coexistem como os lados de uma mesma moeda. Para dar conta desse fenômeno, cunhou os conceitos de "modernidade sólida" e "modernidade líquida".

\footnotetext{
Esta entrevista foi realizada por meios eletrônicos pela professora Alba Porcheddu. O objetivo foi procurar interpretar criticamente, por meio das reflexões de $Z$. Bauman, o diálogo entre Pedagogia e Sociologia a fim de contribuir para a reflexão educativa. Alba Porcheddu é professora de Didática Geral e de Didática e Comunicação do Departamento de Ciências da Educação da Università degli Studi Roma Tre. A entrevista foi publicada originalmente em 2005 pela editora romana Anicia, sob o título Zygmunt Bauman: intervista sull'educazione. Sfide pedagogiche e modernità liquida (www. anicia.it). A Faculdade Latino-Americana de Ciências Sociais/Argentina, a quem agradecemos os originais, publicou posteriormente este trecho em Propuesta Educativa, Buenos Aires, v. 16 n. 28, p.7-18, nov. 2007, traduzido por Mariana Nobile (mariana.nobile@gmail.com).
} 
Pergunta $(P)$ : A educação foi concebida desde o iluminismo como um sistema fortemente estruturado; em tempos mais recentes, a Bildung tem sido interpretada primeiro como um processo, depois até como um "produto" para transmitir e conservar o conhecimento.

No mutável mundo de hoje, onde "correr é melhor que caminhar", onde triunfam entre os jovens a obviedade e as ideologias, o senhor considera ainda plausível uma educação voltada para "fixar em uma forma" a personalidade dos jovens através de um percurso formativo determinado?

Resposta (R): A história da pedagogia esteve repleta de períodos cruciais em que ficou evidente que os pressupostos e as estratégias experimentadas e aparentemente confiáveis estavam perdendo terreno em relação à realidade e precisavam pois ser revistos ou reformados. Todavia, parece que a crise atual é diversa daquelas do passado. Os desafios do nosso tempo infligem um duro golpe à verdadeira essência da ideia de pedagogia formada nos albores da longa história da civilização: problematizam-se as "invariantes" da ideia, as características constitutivas da própria pedagogia (que, incólumes, resistiram às mudanças do passado); convicções nunca antes criticadas são agora consideradas culpadas de ter seguido o seu curso e, portanto, precisam ser substituídas.

No mundo líquido moderno, de fato, a solidez das coisas, tanto quanto a solidez das relações humanas, vem sendo interpretada como uma ameaça: qualquer juramento de fidelidade, compromissos a longo prazo, prenunciam um futuro sobrecarregado de vínculos que limitam a liberdade de movimento e reduzem a capacidade de agarrar no vôo as novas e ainda desconhecidas oportunidades. A perspectiva de assumir uma coisa pelo resto da vida é absolutamente repugnante e assustadora. E dado que inclusive as coisas mais desejadas envelhecem rapidamente, não é de espantar se elas logo perdem o brilho e se transformam, em pouco tempo, de distintivo de honra em marca de vergonha.

Os editores de revistas de amenidades percebem o impulso do tempo: informam regularmente os leitores sobre coisas "para fazer" e "ter" a todo custo, dão-Ihes conselhos sobre aquilo que é out e, portanto, descartável. O nosso mundo lembra cada vez mais a "cidade invisível" de Leônia, descrita por Ítalo Calvino ( 1990), onde "mais do que as coisas que a cada dia são fabricadas, vendidas e compradas, a opulência de Leônia se mede pelas coisas que a cada 
dia são jogadas fora para dar lugar às novas". A alegria de livrar-se das coisas, de descartar e eliminar é a verdadeira paixão de nosso mundo.

A capacidade de durar bastante não é mais uma qualidade a favor das coisas. Presume-se que as coisas e as relações são úteis apenas por um "tempo fixo" e são reduzidas a farrapos ou eliminadas uma vez que se tornam inúteis. Portanto é necessário evitar ter bens, sobretudo aqueles duráveis dos quais é difícil se desprender. $\bigcirc$ consumismo de hoje não visa ao acúmulo de coisas, mas à sua máxima utilização. Por qual motivo, então, "a bagagem de conhecimentos" construída nos bancos da escola, na universidade, deveria ser excluída dessa lei universal? Este é o primeiro desafio que a pedagogia deve enfrentar, ou seja, um tipo de conhecimento pronto para utilização imediata e, sucessivamente, para sua imediata eliminação, como aquele oferecido pelos programas de software (atualizados cada vez mais rapidamente e, portanto, substituídos), que se mostra muito mais atraente do que aquele proposto por uma educação sólida e estruturada.

Em consequência, a ideia de que a pedagogia também possa ser um "produto" destinado à apropriação e à conservação, é uma ideia desagradável e contrária à pedagogia institucionalizada. Para convencer as crianças da importância do conhecimento e do uso da aprendizagem, os pais de antigamente Ihes diziam que "ninguém nunca poderá roubar a sua cultura"; o que soava como uma promessa encorajadora para os filhos de então, seria uma horrenda perspectiva para os jovens de hoje. Os compromissos tendem a ser evitados, a menos que venham acompanhados de uma cláusula de "até nova ordem". [...]

O segundo desafio para os pressupostos basilares da pedagogia deriva da natureza excêntrica e essencialmente imprevisível das mudanças contemporâneas, o que reforça o primeiro desafio. $\bigcirc$ conhecimento sempre foi valorizado por sua fiel representação do mundo, mas o que aconteceria se o mundo mudasse, recusando continuamente a verdade do conhecimento ainda existente e pegando de surpresa inclusive as pessoas "mais bem informadas"? Werner Jaeger', autor de estudos clássicos sobre as antigas origens dos conceitos de

I. Werner Jaeger, filólogo e filósofo, morreu em 1961. Ensinou na universidade de Berlim, Chicago e Harvard. Com numerosas obras publicadas, foi um dos principais filólogos de seu tempo e sua obra principal, Paideia, constitui uma das mais substanciais publicações sobre a Grécia que apareceram no século $X X$ e exprime o grandioso manifesto do chamado terceiro humanismo. 
pedagogia e aprendizagem², acreditava que a ideia de pedagogia (Bildung, formação) tenha nascido de duas hipóteses idênticas: aquela da ordem imutável do mundo que está na base de toda a variedade da experiência humana e aquela da natureza igualmente eterna das leis que regem a natureza humana. A primeira hipótese justificava a necessidade e as vantagens da transmissão do conhecimento dos professores aos alunos. A segunda incutia no professor a autossegurança necessária para esculpir a personalidade dos alunos e, como o escultor com o mármore, pressupunha que o modelo fosse sempre justo, belo e bom, portanto virtuoso e nobre. Se as ideias de Jaeger fossem corretas (e não foram refutadas), significaria que a pedagogia, como a entendemos, se encontraria em dificuldades, porque hoje é necessário um esforço enorme para sustentar essas hipóteses e outro ainda maior para reconhecê-las como incontestáveis.[...]

Segundo o que há muito observou Ralph Waldo³, quando se patina sobre gelo fino a salvação está na velocidade. Seria bom aconselhar àqueles que buscam a salvação a se moverem bastante rápido de modo a não arriscar pôr à prova a resistência do "problema". No mundo mutável da modernidade líquida, onde dificilmente as figuras conseguem manter a sua forma por tempo suficiente para dar confiança e solidificar-se de modo a oferecer garantia a longo prazo (em cada caso, não é possível dizer quando e se se solidificarão e com que pequena probabilidade, no caso de isso ocorrer), caminhar é melhor do que ficar sentado, correr é melhor que caminhar e surfar é melhor que correr. As vantagens do surf estão na rapidez e vivacidade do surfista; por outro lado, o surfista não deve ser exigente ao escolher as marés e deve estar sempre pronto a deixar de lado suas habituais preferências.

Tudo isto não corresponde àquilo que a aprendizagem e a pedagogia superaram na maior parte do seu curso histórico. Afinal, foram criadas na medida de um mundo duradouro, na esperança de que este permanecesse assim e fosse ainda mais durável do que havia sido até então. Em um mundo desse tipo, a memória era um elemento precioso e seu valor aumentava quanto mais

2. Cf. Jaeger ( 1958).

3. Ralph Waldo. nasceu em Boston, em I 803, e morreu em I 882. Ensaísta e poeta americano, autor de Natureza, obra publicada em I836, da qual nasceu o "transcendentalismo", a doutrina idealista que se opunha ao materialismo e à visão calvinista da vida e oferecia, ao mesmo tempo, argumentos a favor da liberdade do indivíduo. Cf. Beniamino Soressi, (2004). 
conseguisse recuar e durar. Hoje esse tipo de memória firmemente consolidada, demonstra-se em muitos casos potencialmente incapacitante, em muitos outros enganosa e quase sempre inútil. É surpreendente pensar até que ponto a rápida e espetacular carreira dos servidores e das redes eletrônicas tem a ver com os problemas de memorização, de eliminação e reciclagem dos descartes que os próprios servidores prometiam resolver; com uma memorização que procurava mais descartes que produtos utilizáveis e sem ter um modo confiável para decidir de antemão quais, entre os produtos aparentemente úteis, se tornariam logo fora de moda e quais, entre aqueles aparentemente inúteis, haveriam de gozar de um súbito crescimento de demanda. A possibilidade de armazenar todas as informações dentro de recipientes mantidos a uma devida distância dos cérebros (onde as informações armazenadas poderiam subrepticiamente controlar o comportamento), parecia uma proposta providencial e atraente.

O problema é que apenas a reforma das estratégias educativas, apesar de engenhosa e completa, pode fazer pouco ou nada. $\bigcirc$ ritual agressivo e repetitivo da corte do spinarello $0^{4}$ ou o repentino chamado da estratégia de vida de Don Giovanni não podem ser atribuídos aos educadores como culpas e negligências. O tipo de mundo para o qual a escola preparava os jovens, como descrito por Myers $^{5}$ ou Jaeger, era diverso daquele que os esperava fora da escola. No mundo de hoje, se espera que os seres humanos busquem soluções privadas para os problemas derivados da sociedade e não soluções derivadas da sociedade para problemas privados.

Durante a fase "sólida" da historia moderna, o cenário das ações humanas era criado para emular, o quanto possível, o modelo do labirinto dos comportamentistas $^{6}$, no qual a diferença entre os caminhos certos e errados era clara e fixa, de modo que aqueles que erravam ou recusavam os caminhos

4. Spinarello: trata-se de um pequeno peixe de água doce agilíssimo. $\bigcirc$ macho constrói o ninho e durante o cortejo assume uma esplêndida cor vermelha com a qual sinaliza à fêmea, mas também a eventuais pretendentes, a sua intenção.

5. Edward D Myers ocupa-se da história da civilização helênica. Zigmunt Bauman refere-se em particular ao ensaio Education in the perspective of history (1960).

6. $\bigcirc$ autor se refere aos experimentos dos behavioristas que usavam o labirinto, com seus percuros cegos ou abertos, no estudo da aprendizagem dos ratos e, como se verá adiante, às leis skinnerianas da "aquisição" segundo as quais um comportamento operante se fixa na memória através de um estímulo de reforço. 
certos eram constante e imediatamente punidos, enquanto aqueles que os seguiam obediente e velozmente eram recompensados. Na época moderna as grandes fábricas "fordistas" e o recrutamento de massas para os exércitos, os dois braços mais longos do poder panótico ${ }^{7}$, eram a personificação completa da tendência à rotina dos estímulos e da reação aos estímulos. $\bigcirc$ "domínio" consistia no direito de estabelecer leis infringíveis, vigiar o seu cumprimento, determinar obrigações para se seguir sob vigilância, realinhar os desviantes ou excluí-los, no caso do fracasso do esforço de reformá-los. Esse modelo de dominação exigia um compromisso recíproco e constante dos administradores e dos administrados. [...] A modernidade "sólida" era verdadeiramente a era dos princípios duradouros e concernia, sobretudo, aos princípios duráveis que eram conduzidos e vigiados com grande atenção.

Na fase "líquida" da modernidade, a demanda por funções de gestão convencionais se exaure rapidamente. A dominação pode ser obtida e garantida com um dispêndio de energia, tempo e dinheiro muito menor: com a ameaça do descompromisso, ou da recusa do compromisso, mais do que com um controle ou uma vigilância inoportunos. A ameaça do descompromisso arrasta o onus probandi para o outro lado dominado. Agora, cabe aos subordinados comportar-se de modo a obter consensos perante os chefes e levá-los a "adquirir" seus serviços e seus produtos criados individualmente (assim como os outros produtores e comerciantes procuram persuadir os prováveis clientes a desejar as mercadorias à venda). "Seguir a rotina" não seria suficiente para alcançar esse objetivo. Como descobriu Luc Boltanski e Ève Chiapelo (1999).

7. Durante o lluminismo, Jeremy Bentham chamou de "panótico" um edifício que prevê em seu centro uma torre de observação. O vigia que a ocupa pode, através de um engenhoso jogo de luzes e sombras, controlar o espaço circular circundante sem ser visto pelos habitantes. Ele é o Um que tudo observa. A aplicação evidente desse projeto era a construção de prisões, hospitais e também manicômios, mesmo Bertham não sendo totalmente consciente do alcance de sua invenção. A aliança entre o poder político e as técnicas de controle e de manipulação sempre tentaram recriar as condições do panopticon. A construção e difusão das mensagens por parte de centros de poder (que ocupam a torre de controle do panopticon) nos propõem cotidianamente chaves interpretativas da realidade verossímeis, mas não verdadeiras.

8. Luc Boltanski é diretor da Ecole des Hautes Études en Sciences Sociales de Paris; Ėve Chiapello é professora associada na École de Hautes Études Commerciales de Paris. A obra deles se ocupa, como os próprios autores afirmam, das mudanças ideológicas que acompanharam as transformações recentes do capitalismo: "O nosso objetivo seria aquele de responder a uma crescente pergunta do pensamente critico suscetível de dar forma à inquietação social difusa 
quem quiser obter sucesso na organização que substituiu o modelo dos princípios da ocupação que podemos definir como "labirinto para ratos", deve demonstrar jovialidade e capacidade comunicativa, abertura e curiosidade, pondo à venda a própria pessoa, no seu todo, como valor único e insubstituível para aumentar a qualidade da equipe. Agora é tarefa dos empregados, atuais ou futuros, se "autocontrolarem" para garantir serviços convincentes e provavelmente aprovados, mesmo nos casos de mudança do gosto dos observadores; ao contrario, os chefes não são obrigados a reprimir as idiossincrasias de seus subordinados, a homogeneizar os seus comportamentos nem encerrar suas ações no interior da rígida estrutura da rotina.

No passado, a pedagogia assumiu diversas formas e se mostrou capaz de adaptar-se às mudanças, de fixar-se novos objetivos e criar novas estratégias. Todavia, deixe-me repetir que as mudanças de hoje são diferentes daquelas ocorridas no passado. Nenhuma reviravolta da história humana pôs os educadores diante de desafios comparáveis a esses decisivos de nossos dias. Simplesmente não havíamos estado até agora em situação semelhante. A arte de viver em um mundo ultrassaturado de informações ainda deve ser aprendida, assim como a arte ainda mais difícil de educar o ser humano neste novo modo de viver.

P: Segundo sua interpretação, o sinótico, substituto do pré-moderno panótico, é o instrumento principal de conservação dos modelos tradicionais. Mas, sobretudo, o senhor afirma que terminou a época heróica dos "chefes espirituais": os "missionários" que elaboravam o projeto de vida ao qual professores, educadores, censores deveriam referir-se. Qual é então o papel dos profissionais da educação de hoje diante dos novos desafios postos pela passagem da modernidade sólida àquela líquida? E quais exigências pedagógicas resultam proeminentes? Qual é portanto o papel da educação e de seus profissionais?

R: Proponho a única resposta imaginável a esta pergunta, posta nos lábios de Marco Polo pelo célebre Italo Calvino:

e fornecer, pelo menos, instrumentos de inteligibilidade e, na melhor das hipóteses, uma orientação para a ação, isto é, neste caso, uma esperança". 
- O inferno dos vivos não é algo que será; se existe, é aquele que já está aqui, o inferno no qual vivemos todos os dias, que formamos estando juntos. Existem duas maneiras de não sofrer o inferno. A primeira é fácil para a maioria das pessoas: aceitar o inferno e tornar-se parte dele até o ponto de deixar de percebê-lo. A segunda é arriscada e exige atenção e aprendizagem contínuas: tentar saber reconhecer quem e o que, no meio do inferno, não é inferno, e preservá-lo, e abrir espaço. (1990, p. I50)

Se viver em uma sociedade de caçadores é ou não é como viver em um inferno é obviamente uma questão controversa (a maior parte dos caçadores afirma que ser um caçador entre os caçadores tem também os seus bons momentos). Aquilo que, ao contrário, é raramente assunto de discussão é o fato que "muitos" escolherão a estratégia "fácil para muitos" e dela se tornarão parte integrante, sem já não se sentirem mais desconcertados pela sua lógica bizarra, nem enfastiados por suas pretensões mutáveis e constantes.

É incontestável que a perspectiva que os educadores em busca de "o que ou quem não é o inferno" acabem se defrontando com uma tarefa árdua na tentativa de chamar a atenção e de promover o espírito crítico nos próprios alunos. É certo que esses educadores estão submetidos a fortes pressões que os levam a aceitar aquilo que eles mesmos obstinadamente insistem em definir como inferno e induzem os alunos a aplicar, para torná-la ainda mais fácil, a própria estratégia de vida que se pode definir como: "fácil para muitos".

Retomando Gregory Bateson ( 1976), relembremos que a "aprendizagem terciária" (que promove a formação de competências de modo a desmantelar os esquemas cognitivos aprendidos antes), reduz os alunos ao nível do plâncton, transportado por ondas casuais e sem encontrar um lugar onde permanecer ou apoiar-se para resistir à maré. Desse modo a aprendizagem terciária parece

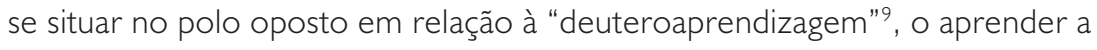
aprender. Esta, de fato, segundo Bateson, poderia permitir aos discentes "lançar bases sólidas", integrando as noções adquiridas a novos conhecimentos, per-

9. O autor afirma que para Bateson a deuteroaprendizagem, o "aprender a aprender", é inevitável mas cumpre com sua função (adaptadora) em relação aos atributos do mundo no qual estão destinados a viver os estudantes mais do que conectados à sua própria diligência. Depois, Bateson sente a necessidade de completar o conceito introduzindo a aprendizagem terciária. Cf. Z. Bauman (2002). 
mitindo a eles prosseguir pela trajetória escolhida em todas as circunstâncias, até nas mais voláteis. Se a deuteroaprendizagem torna a conduta dos alunos autônoma, a aprendizagem terciária está destinada a confundir-lhes e a tornar seu comportamento heterogêneo. A aprendizagem terciária não deixa um sedimento duradouro, uma base sólida sobre a qual se pode construir, tampouco conhecimentos que podem sedimentar-se e crescer durante o curso dos estudos. $\bigcirc$ processo de aprendizagem terciária (presumindo-se que se possa falar de processo em tal caso) é uma sucessão infinita de novos inícios, devida antes de tudo ao rápido cancelamento dos conhecimentos pregressos, mais que à aquisição de novos conhecimentos; parece uma espécie de cruzada contra a manutenção e a memorização dos conhecimentos. A aprendizagem terciária poderia, assim, ser definida como um dispositivo antimemória. É por isso que Gregory Bateson definiu a aprendizagem terciária como uma patologia, uma formação cancerígena que cresce nutrindo-se no corpo da instrução e, se não extirpada, leva à sua destruição.

Contudo, o pressuposto sobre o qual se funda o veredicto de Bateson não reina mais; em uma modernidade líquida se tornou por assim dizer contrafactual. A aprendizagem terciária parece provavelmente patológica, entre surto de loucura e potencialmente suicida, só porque combina com o argumento de que a vida de cada um, inconstante e relativamente breve, é inscrita em um mundo estável e imperecível. Em uma modernidade líquida, contudo, a relação entre a vida e o mundo sofreu uma reviravolta; se parte agora do argumento contrário, no qual a vida do indivíduo, relativamente longa, é dedicada à sobrevivência em condições frágeis e voláteis através de uma série de "novos inícios" sucessivos. [...]

Os praticantes de uma vida fatiada em episódios, cada um dos quais com um novo início e um fim brusco, não têm necessidade de uma educação que busque lhes fornecer os instrumentos idôneos para um mundo invariável (ou para um mundo que se move a uma velocidade inferior em relação àquela do conhecimento ao qual deveria estar ligada). Os caçadores levam a própria vida, fugindo, deslocando-se de uma floresta a outra; assim como todos nós vivemos passando de um projeto a outro, do projeto ainda por definir ao projeto apenas terminado, como demonstraram de maneira convincente Luc Boltanski e Eve Chiapello. Não nos preocupamos com a velocidade impressionante com que o conhecimento muda de ritmo, o conhecimento precedente envelhece e o 
novo, recém-nascido, é destinado a envelhecer do mesmo modo: a volatilidade do mundo líquido, parcamente integrado e multicêntrico, faz com que cada um dos episódios sucessivos dos projetos conduzidos na vida requeiram uma série de competências e informações que tornam vãs as competências pregressas e as informações memorizadas. Aprender quantidades excessivas de informações, procurando absorvê-las e memorizá-las, aspirando tenazmente à completude e à coesão das informações adquiridas, é visto com suspeita, como uma ilógica perda de tempo... [...]

Tudo isso contradiz a verdadeira essência da educação centrada na escola, que notoriamente prefere um rígido programa de estudos e uma sucessão predefinida no processo de aprendizagem. Na modernidade líquida os centros de ensino e aprendizagem estão submetidos à pressão "desinstitucionalizante" e são continuamente persuadidos a renunciar à sua lealdade aos "princípios do conhecimento" (sua existência, para não falar de sua utilidade, é sempre posta em dúvida), valorizando ao contrário a flexibilidade da presumida lógica interna das disciplinas escolares.

As pressões provêm seja do alto (do governo que pretende acompanhar os caprichosos e voláteis movimentos no mundo econômico), seja de baixo (dos estudantes, expostos igualmente às caprichosas demandas do mercado de trabalho e desconcertados por sua natureza aparentemente casual e imprevisível). Outro fator, a perda do tradicional monopólio das instituições escolares no papel de tutoras do conhecimento e da relativa partilha de (ou concorrência por) de tal papel com os fornecedores de software para computador, revigora tais pressões.

Um efeito muito evidente dessas pressões, verificado pelos teóricos e integrantes do sistema educacional, é o evidente deslocamento de ênfase do "ensino" à "aprendizagem". Imputar aos estudantes a responsabilidade de determinar a trajetória do ensino e da aprendizagem (e, portanto, de suas consequências pragmáticas) reflete a crescente falta de vontade dos alunos de assumir compromissos de longo prazo, reduzindo assim o leque de opções futuras e limitando o âmbito de ação. Outro efeito evidente das pressões desinstitucionalizantes é a "privatização" e a "individualização" dos processos e das situações de ensino e aprendizagem, além da gradual e inexorável substituição da relação ortodoxa professor-aluno por aquela de fornecedor-cliente, ou aquela centro comercial-comprador. 
Este é o contexto social no qual estão obrigados a trabalhar atualmente os educadores. As suas respostas e a eficácia das estratégias utilizadas para promover tais respostas são destinadas a permanecer por longo tempo objeto crucial de estudo das ciências pedagógicas.

P: Das suas reflexões sobre educação parece emergir a tese de que a prática educativa deve abandonar os modelos fortemente estruturados, em favor de um processo formativo aberto. É possível projetar uma intervenção formativa sem poder determinar desde o início objetivos didáticos e educacionais precisos?

R: Desde que os antigos sábios gregos inventaram a noção de Paideia foi preciso mais de dois mil anos para transformar a ideia de "educação permanente", de oxímoro (contradição dos termos) em pleonasmo (do tipo "manteiga amanteigada", "ferro metálico"...). Entretanto, a atestação dessa notável transformação ocorreu recentemente - nos últimos dez anos - sob o impacto da mudança acelerada do ambiente social no qual os protagonistas principais da educação (tanto professores como educandos) deviam agir.

Contemporaneamente, também em outros setores, mas com a mesma modalidade acelerada, surgiram outras mudanças.

Para os mísseis balísticos, no momento em que começam a "se mover", a direção e a distância de sua viagem já são decididas pela forma e pela posição do canhão; pela quantidade de pólvora no projétil, é possível calcular, com margem mínima ou inexistente de erro, o ponto de aterrissagem, ou até mesmo alterálo, modificando a posição do canhão ou a quantidade de pólvora do disparo. Essa propriedade dos mísseis balísticos os torna armas ideais para se utilizar em caso de uma guerra de posição, ou quando os alvos se encontram entrincheirados ou nos bunkers e os mísseis são os únicos corpos em movimento.

As mesmas qualidades os tornam entretanto também inúteis uma vez que os alvos começam a se mover, tornando-se invisíveis às armas, sobretudo quando esses alvos se movem mais rapidamente do que os mísseis podem "voar" e, ainda mais, se se movem de um modo irregular ou imprevisível, que desnorteiam todos os cálculos preliminares da trajetória requerida. É então necessário um míssil inteligente, que possa modificar a sua direção em vôo com base na evolução dos eventos, que possa individualizar imediatamente os 
movimentos dos alvos, aprender tudo o que for necessário sobre a direção e a velocidade real do alvo e identificar, a partir das informações recolhidas, o ponto para o qual direcionar a sua trajetória. Durante a viagem, esses mísseis inteligentes não podem interromper, muito menos finalizar, a coleta e a elaboração das informações, já que os alvos continuam a se mover e a modificar suas direções e velocidades, e o ponto de encontro observado deve ser constantemente atualizado e retificado.

Podemos dizer que os mísseis inteligentes seguem a estratégia da "racionalidade instrumental”, entendida na sua versão líquida, fluida; isto significa que se abandona o pressuposto de que o objetivo seja estabelecido, fixo e irremovível durante toda a duração do lançamento e que portanto devem ser calculados e manipulados somente os instrumentos de vôo. Também a utilização de mísseis ainda mais inteligentes não será limitada a alvos preestabelecidos, mas a alvos escolhidos no ar. Tais mísseis serão sobretudo guiados considerando-se o máximo que podem atingir dadas suas capacidades técnicas e o número de alvos que potencialmente podem acertar de acordo com seu equipamento. Em suma, podemos dizer que este seria justamente o caso contrário à "racionalidade instrumental": os alvos são selecionados com os mísseis no ar e são os meios disponíveis que decidirão qual será, ao final, a "meta" a se escolher. [...]

Os mísseis inteligentes, portanto, diferentemente dos velhos artefatos balísticos, aprendem no ar. Assim, devem ser inicialmente dotados da capacidade de aprender e de aprender de modo rápido. Isso é óbvio. O que é menos evidente, se bem que não menos importante dentro de uma rápida capacidade de aprendizagem, é todavia a capacidade de esquecer instantaneamente o que se aprendeu antes. Os mísseis inteligentes não seriam inteligentes se não fossem capazes de "mudar de ideia", ou de revogar as "decisões" precedentes, sem pensar duas vezes e sem remorsos... Não deveriam se preocupar com as informações adquiridas e por nenhuma razão deveriam desenvolver um hábito comportamental sugerido pelas informações. Todas as informações obtidas "envelhecem" rapidamente e ao invés de fornecerem um guia confiável podem desviar do caminho se não forem prontamente ignoradas. Aquilo que os "cérebros" dos mísseis inteligentes não devem nunca esquecer é que o conhecimento adquirido é eminentemente eliminável, somente eficaz até uma nova ordem e útil apenas temporariamente, e que a demonstração do sucesso está em não deixar escapar o momento em que o conhecimento adquirido não é mais útil e deve ser eliminado, esquecido e substituído. 
Deixe-me extrair desse exemplo muito articulado a seguinte consideração: os filósofos da educação da era sólido-moderna consideravam os professores como lançadores dos mísseis balísticos e os instruíam sobre como se assegurar que seus produtos seguissem rigorosamente na rota preestabelecida, determinada desde o início pela quantidade de movimentos do lançamento. E não é de se surpreender, visto que os mísseis balísticos eram, durante a primeira fase da era moderna, a invenção tecnológica humana mais avançada. Estes serviram impecavelmente a quem quisesse conquistar e governar o mundo, como declarou Hilaire Belloc ${ }^{10}$ referindo-se aos nativos africanos. "Qualquer coisa que ocorra temos a Metralhadora Maxim e eles não a têm" (a metralhadora Maxim era uma arma capaz de lançar um grande número de projéteis balísticos em pouco tempo e era muito eficaz, mas somente se se possuía um grande número de projéteis).

Em realidade, essa visão da tarefa do professor e do destino do aluno é muito anterior à ideia de "míssil balístico" e da era moderna que a inventou - como diz um antigo provérbio chinês de mais de dois mil anos antes do advento da modernidade mas ainda citado pela Comissão Europeia em apoio ao programa Lifelong Learning, no limiar do século XXI: "Quando planejas por um ano, semeias o grão. Quando planejas por uma década, plantas árvores. Quando planejas por uma vida inteira, formas e educas as pessoas".

Somente com o advento dos tempos líquido-modernos a antiga sabedoria perdeu seu valor pragmático e as pessoas envolvidas no âmbito da aprendizagem e da promoção da aprendizagem, âmbito conhecido com o nome de "educação", têm deslocado sua atenção dos mísseis balísticos para aqueles inteligentes.

A educação e a aprendizagem no ambiente líquido-moderno, para ser úteis, devem ser contínuas e durar toda a vida. Nenhum outro tipo de

10. Joseph-Pierre Hilaire Belloc é definido como um escritor católico entre dois mundos; nasce em 1870, em Paris, e falece em 1953 na Inglaterra, com pai francês, advogado, e mãe inglesa, pertencente à alta burguesia e convertida do protestantismo ao catolicismo. Teve um temperamento combativo, declarando abertamente ao final de sua juventude a sua adesão ao catolicismo. Polemista muito ativo no debate político (em 1906 e em 1910 é eleito para a Câmara dos Comuns na Inglaterra); escritor prolífico em vários gêneros, da narrativa à poesia, da técnica militar aos romances policiais. Uma citação famosa de Hilaire Belloc sustenta que Roma abateu a potência de Cartago, assim perecendo por alguns séculos a danosa ilusão de que o mercador podia dominar o soldado! 
educação e/ou aprendizagem é concebível; a "formação" do próprio eu, ou da personalidade, é impensável de qualquer outro modo que não seja aquele contínuo e perpetuamente incompleto.

P: Da estreita relação que emerge entre a formação e o mercado resulta que a educação é necessária, mas também que o indivíduo deve tornar-se capaz de escolher entre as inumeráveis ofertas formativas para ser competitivo. Por que o senhor sustenta que a educação permanente é a única atualmente possível, quais são as reais possibilidades de desenvolvimento dessa perspectiva educativa?

R: Jacek Wojciechowskil' (editor de revista polonesa sobre a profissão acadêmica) observa que

... antes a diplomação universitária oferecia regras seguras para praticar a profissão até a aposentadoria, mas hoje isso é passado. Atualmente o conhecimento necessita ser constantemente renovado e também as profissões necessitam de mudanças, senão todos os esforços para sobreviver seriam vãos. (2004)

Em outras palavras, o crescimento impetuoso do novo conhecimento e o envelhecimento igualmente rápido do velho se combinam para produzir, em larga escala, ignorância humana que continuamente reabastece (e até mesmo alimenta) as suas provisões.

Wojciechowski adverte: onde existe um problema e as pessoas lutam para resolvê-lo, o mercado virá prontamente em seu socorro. Por um preço alto, obviamente. Nesse caso, o problema é a ignorância das pessoas: um golpe de sorte para os vendedores e azar dos compradores. Para os hábeis diretores de escolas, isso constitui ocasião oportuna para recolher fundos, promovendo cursos para o desenvolvimento das capacidades atualmente demandadas, ainda que os professores com a capacidade necessária para transmiti-las brilhem por não tê-las. Este é o mercado dos fornecedores, dos clientes em potencial que,

I I. Jacek Wojciechowski é oriundo da cátedra de Gestão e Comunicação Social da Universidade Jagellonika de Cracóvia; também é responsável pela Informação Científica da universidade e ainda Diretor da Biblioteca Wojewodzka de Cracóvia. 
por definição, não estão em condições de julgar a qualidade dos produtos em oferta ou se tornam pedantes se se arriscam a fazê-lo. Inferior ou inútil, às vezes antiquado ou enganoso, o conhecimento é facilmente vendido e quanto mais é adquirido, menos provável que os enganados descubram o jogo. Wojciechowski deixa entender que o único tipo de curso de "educação contínua" que deveria ser oferecido, experimentalmente, pelas instituições sem as devidas credenciais, seria aquele de odontologia, desde que os professores fossem os pacientes nos ambulatórios.

Expoliar a ignorância humana e a credulidade garante retornos imediatos e seguros e sempre haverá um caçador de fortuna incapaz de resistir a tal promessa. Todavia, mesmo deixando de lado o perigo genuíno, difuso e sempre maior do comércio desonesto, a velocidade com a qual as capacidades adquiridas e as demandas do mercado da mão-de-obra/trabalho se desvalorizam, permite inclusive às pessoas irrepreensivelmente honestas de contribuir (ainda que, neste caso, mais por lassidão que por propósito) com as desagradáveis repercussões sociais da nova e grande dependência do conhecimento. Como recentemente percebido por Liz Thomas (2004), a comercialização da educação indispensável de meio de carreira aumenta as diferenças sociais e econômicas existentes entre uma elite de trabalhadores altamente instruída e qualificada e o resto da força de trabalho e também entre a mão de obra especializada e aquela não especializada, criando novas e insuperáveis barreiras à mobilidade social e aumentando o desemprego e a pobreza; uma vez estabelecidas, as diferenças tendem a se perpetuar e se retroalimentarem. [...]

Isso foi pressuposto pela Comissão Europeia e confirmado na comunicação já citada Making a European area of lifelong learning a reality [Fazer da educação permanente na Europa uma realidade], publicada em 2 I de Novembro de 200।, se bem que não seja totalmente certo que as consequências sociais da comercialização da educação em curso fossem a preocupação principal a inspirar a iniciativa. O tema dominante de todo o documento é a suspeita de que a educação permanente administrada pelo mercado não forneceria aquilo que realmente serve à "economia" e pode, portanto, incidir desfavoravelmente sobre a eficiência e a competitividade da União Europeia e de seus países-membros.

Os autores do documento estão preocupados pelo fato de que o advento da "sociedade do conhecimento" seja presságio de enormes riscos para seus potenciais utilizadores; essa "ameaça de ser a causa de diferenças e exclusões sociais ainda maiores”, visto que só 60,3\% da população da União Europeia, 
de idade compreendida entre 25 e 64 anos, completou ao menos a educação de nível médio, enquanto 150 milhões de pessoas na União Europeia não possuem esse nível básico de educação e "estão expostos a um risco maior de marginalização". Mas a necessidade de expandir a educação/aprendizagem permanente é discutida, desde o início do documento, em termos de "vantagem competitiva" que "depende cada vez mais de investimento em capital humano" e do conhecimento e das competências, tornando-se "um potente motor para o crescimento econômico”. Segundo a comissão, a importância e a necessidade de uma aprendizagem permanente consiste em seu papel de "promoção de uma força de trabalho qualificada, formada e adaptável". A tarefa de chegar a uma sociedade "mais global, tolerante e democrática" marcada por "maior participação cívica, um bem-estar maiormente declarado e uma criminalidade menor" se insere nesse raciocínio sobretudo como uma lembrança, como um efeito colateral: expressa-se a esperança que aconteça como uma consequência natural o fato de que mais gente formada, no lugar daquela formada inadequadamente, "faça o seu ingresso no mercado de trabalho" graças a uma formação aperfeiçoada.

[...] Uma mudança educacional está cada vez mais ligada ao discurso da eficiência, da competitividade, do custo/eficácia e da "responsabilidade", sendo sua meta declarada comunicar à "força de trabalho" as virtudes da flexibilidade, da mobilidade e "as competências de base associadas ao emprego".

P: O senhor falou de "comercialização da educação em curso" e do diálogo já quase exclusivo do mundo da formação com o mundo do trabalho e com as dinâmicas econômicas. As inquietações dos pedagogos quanto a esse cenário emergem em todos os âmbitos da pesquisa acadêmica. Essas inquietações se referem à questão da necessidade de mudança da abordagem educativa diante da liquefação dos modelos de referência, e também ao problema da "individualização" da questão pedagógica, fenômeno que ganha sempre maior terreno. Em que sentido e como é possível que a educação se reduza a ser quase exclusivamente "formação para o trabalho" inclusive no nível das diretivas europeias?

R: As inquietações têm fundamento. É simples traçar as extraordinárias afinidades entre a abordagem utilizada pela Comissão Europeia e as intenções 
e demandas declaradas abertamente por autores que escreveram explicitamente em nome e em prol dos executivos de empresas. Estes seguem com algumas modificações o modelo de raciocínio exemplificado por um compêndio muito popular e influente no pensamento empresarial (Fombrun, Tichy, Devana, 1984) segundo o qual o objetivo da educação é o de "desenvolver trabalhadores, ou seja, aumentar sua cota atual de trabalho e prepará-los para as tarefas que poderão desenvolver no futuro." Esse desenvolvimento deve sempre ser determinado pela "individualização das competências necessárias e pela gestão ativa do aprendizado do trabalhador para um futuro a longo prazo, em relação com estratégias empresariais explícitas". Raili Moilanen (2004), depois de ter analisado os conteúdos dos documentos submetidos à Terceira Conferência Internacional de Pesquisa sobre o Trabalho e a Aprendizagem que representavam o ponto de vista dos trabalhadores, conclui que "o aprendizado e o desenvolvimento parecem ser importantes para as organizações sobretudo por razões de eficácia e competitividade" enquanto "o ponto de vista do ser humano como tal parece não ser importante".[...]

Os apelos ao papel central do desenvolvimento dos recursos humanos (Human Resources Development) baseados na "individualização das competências necessárias para o mercado de trabalho" foram feitos inúmeras vezes antes com exemplar coerência; com regularidade igualmente monótona os gerentes dos "recursos humanos" não conseguiam antecipar quais seriam as "exigências" do "mercado de trabalho" no momento em que a "força de trabalho" tivesse completado a formação e estivesse presumivelmente pronta para o emprego. Os desenvolvimentos imprevistos da demanda do mercado não são facilmente prognosticáveis, tanto que os especialistas de previsões não são ingênuos e os seus prognósticos são metodologicamente previstos. Os erros de previsão da demanda do mercado causam terror e provavelmente representam o mal incurável de todas as "previsões científicas" das progressões sociais; mas nesse caso, em que as perspectivas de vida humana estão em risco, juízos errados são extraordinariamente nocivos. Confiar os esforços pessoais em prol da imposição e do desenvolvimento de si mesmo a visões essencialmente imprevisíveis - e assim declaradamente pouco confiáveis - das exigências futuras do mercado mutável e caótico, faz pressagiar um grande sofrimento humano associado a frustração, esperanças vãs e vida desperdiçada. Os cálculos preventivos do "poder humano" requerem uma autoridade que não possuem, fazem promes- 
sas que não podem manter e consequentemente assumem responsabilidades que não podem sustentar.

Provavelmente, tudo isso ocorre também porque os programas de "educação permanente" tendem a ser remanejados, imperceptivelmente e sem explicações explícitas, exaltando-se a "aprendizagem permanente". Isso se torna portanto um "auxílio" às responsabilidades associadas à seleção e à aquisição das competências e, em particular, associadas às consequências das escolhas erradas por aqueles que são parte receptora dos "mercados de trabalho", notoriamente fluidos e mutáveis. Borg e Mayo estão no caminho certo quando concluem que

\begin{abstract}
...nestes tempos rigorosamente neoliberais, a noção de aprendizagem autogestionada se presta a um discurso que consente ao Estado a renúncia de sua responsabilidade de fornecer a educação de qualidade que cada cidadão de uma sociedade democrática tem o direito de possuir.
\end{abstract}

Deixe-me ainda evidenciar que essa não é a primeira nem a última função que o Estado gostaria de eliminar de bom grado do reino da política e, consequentemente, das suas responsabilidades. Deixe-me acrescentar ainda que a ênfase mutável, que se desloca da categoria da "educação" para a de '"aprendizagem", está em harmonia com uma outra tendência, comum entre os empresários contemporâneos: a inclinação a descarregar sobre as costas dos trabalhadores todas as suas responsabilidades, mas sobretudo os efeitos negativos e, mais geralmente, a responsabilidade do "fracassado crescimento da mudança".

Dada a contínua convergência desses dois caminhos tempestuosos que dirigem, na era líquido-moderna, as relações de poder e a estratégia de domínio, as perspectivas de retomada do percurso controvertido e errático do desenvolvimento do mercado, bem como aquelas de cálculos mais realistas para os "recursos humanos" são escassas na melhor das hipóteses e, mais provavelmente, nulas. No ambiente líquido-moderno, a "incerteza produzida" é o instrumento de domínio mais importante quando a política de precarização, usando o termo de Pierre Bourdieu (um conceito que se refere às manobras resultantes da situação em que os sujeitos se tornam mais inseguros e vulneráveis e por isso ainda menos previsíveis e controláveis), se torna rapidamente 
o núcleo da estratégia de domínio ${ }^{12}$. O mercado e a "planificação da vida" são antitéticos e uma vez que a política se deixa guiar pela "economia", entendida como jogo livre das forças de mercado, o equilíbrio do poder entre os dois se desloca decididamente em direção ao primeiro.

Tudo isso não é de bom augúrio para a "concessão dos poderes aos cidadãos", definido pela Comissão Europeia como o objetivo principal da educação permamente. Segundo o consenso geral, a "outorga dos poderes" (expressão utilizada nas atuais bases de dados e intercambiável por "autorização") se obtém quando as pessoas adquirem a capacidade de controlar, ou ao menos de influir sobre as forças individuais, políticas, econômicas e sociais que poderiam incidir no curso de suas vidas. Para dizer francamente, uma "autorização" autêntica requer não apenas a aquisição das capacidades que consentiriam em fazer parte do jogo criado por outros, mas também a aquisição de poderes tais que permitam influenciar os objetivos, os lugares e as regras do jogo. Obviamente, falamos de capacidades não apenas individuais mas também sociais.

P: Somos pois uma sociedade "do conhecimento e da aprendizagem contínuos", mas também das inquietações relativas à exigência de conviver cotidianamente com a incerteza, a ausência de autoridade, a solidão e a precariedade. Somos, porém, constantemente também obrigados a fazer escolhas e agir. Com tais pressupostos, é possível considerar a cultura democrática (do respeito à pluralidade dos pontos de vista até o direito dos outros a ser diferentes) como o pilar da instrução de amanhã?

R: Como já disse, a outorga dos poderes aos cidadãos requer a capacidade de fazer escolhas e de agir eficazmente com base nas escolhas feitas, mas requer também a construção e a reconstrução de vínculos interpessoais, a vontade e a capacidade de empenhar-se continuamente junto com os outros

12. Pierre Bourdieu, falecido em 2002, afirma que "A precarização e a flexibilização provocam a perda das pequenas vantagens (frequentemente descritas como privilégios de 'endinheirados') que poderiam compensar os baixos salários, como o emprego durável, as garantias de saúde e de aposentadoria" (Cf. Bordieu, 1988. Também em http://www.pages-bourdieu.fr.st/). Titular por cerca de trinta anos da cátedra de Sociologia no Collège de France e sempre muito crítico em relação a cada establishment, Bourdieu faz parte dos estudiosos que se esforçaram em demonstrar os limites da globalização. 
para criar uma convivência humana em um ambiente hospitaleiro e amigável: e, ainda, exige uma cooperação entre os homens e as mulheres na luta pela autoestima, voltada para o enriquecimento recíproco, para o desenvolvimento das potencialidades dos diversos sujeitos e para o desfrute adequado das suas capacidades. Em resumo, um dos desafios decisivos da educação permanente para a "outorga de poderes" está ligado à reconstrução do espaço público hoje cada vez mais desabitado, onde homens e mulheres possam empenhar-se em uma realização contínua dos interesses, dos direitos e dos deveres individuais e comunitários, privados e públicos.

"À luz dos processos de fragmentação e segmentação e da crescente diversidade individual e social", escreve Dominique Simon Rycher (2004), "o reforço da coesão social e o desenvolvimento de um senso de sabedoria e responsabilidade social se tornaram importantes objetivos sociais e políticos". No ambiente de trabalho, na vizinhança e na rua, nos mesclamos cotidianamente com outros que, enfatiza Rycher, "não falam necessariamente a nossa língua (literal ou metaforicamente) ou não compartilham a nossa história e o nosso passado". Nessa situação, a capacidade de que temos mais necessidade para oferecer à esfera pública uma justa possibilidade de renascimento é a capacidade de interação com os outros: o diálogo, a negociação, a gestão e a resolução dos conflitos, inevitáveis em todos os exemplos de vida em comum.

Gostaria de repetir o que foi dito no começo: no ambiente líquidomoderno, a educação e o aprendizado, não importa o uso que se faça deles, devem ser contínuos e permanentes. O motivo determinante para o qual a educação deve ser contínua e permanente está na natureza da tarefa que devemos desenvolver no caminho comum da "outorga dos poderes", uma tarefa que é exatamente como deveria ser a educação: contínua, ilimitada, permanente.

Uma tarefa que, como a educação, deveria ser para o bem dos homens e mulheres líquido-modernos, capazes de procurar alcançar os próprios objetivos com ao menos um pouco de independência, segurança de si mesmos e esperança de sucesso. Mas há outro motivo que, apesar de menos discutido, é mais eficaz: trata-se de não adaptar as capacidades humanas ao ritmo desenfreado das mudanças do mundo, e sobretudo de tornar o mundo, em contínua e rápida mudança, mais hospitaleiro para a humanidade. Essa tarefa requer uma educação contínua e permanente. Como recordaram recente- 
mente Henry A. Giroux ${ }^{13}$ e Susan Searls Giroux (2003), a democracia está em perigo porque os indivíduos são incapazes de transformar a sua miséria, sofrida privadamente, em fatos de amplo domínio público e de ação coletiva. À medida que as companhias multinacionais definem o conteúdo da maior parte das mídias tradicionais, a privatização do espaço público e o compromisso cívico aparecem mais impotentes e os valores públicos ficam cada vez mais invisíveis. Hoje, para muitas pessoas, as ações da cidadania se limitam à aquisição e à venda de bens (inclusive para os candidatos à própria vida pública), em vez de aumentar o alcance de sua liberdade e dos seus direitos a fim de ampliar os atos de uma verdadeira democracia.

O consumidor é um inimigo do cidadão... Em todas as regiões "desenvolvidas" e ricas do planeta há numerosos exemplos de pessoas que voltam as costas para a política, numa apatia política e numa perda de interesse em relação aos processos políticos cada vez mais maiores. Mas os políticos democráticos não podem sobreviver por muito tempo à passividade dos cidadãos, originada na ignorância e na indiferença política. As liberdades dos cidadãos não são propriedades que se adquirem uma vez por todas; elas não estão seguras, encerradas nas suas caixas-fortes. São plantadas e enraizadas no terreno sociopolítico, que precisa ser cotidianamente fertilizado e que se torna árido até ficar gretado, se não for cuidado dia após dia com as ações informadas de um público preparado e comprometido. Não é preciso atualizar só as capacidades técnicas, não é só a educação voltada para o trabalho que precisa ser permanente. $\bigcirc$ mesmo vale, com uma urgência ainda maior, para a educação para a cidadania.

Muitas pessoas hoje concordariam, sem muita insistência, com o fato de que os seus conhecimentos profissionais necessitam de atualização e que precisam assimilar novas informações técnicas para não ser "deixadas para trás" e fora do "progresso tecnológico" em contínua evolução. Esse senso de urgência falta justamente no momento em que é preciso se atualizar em relação aos desenvolvimentos políticos e à rápida mudança das regras do jogo

13. Giroux é Waterbury Chair of Secondary Education na Pennsylvania State University. De 1977 a 1983 foi docente na Boston University e em seguida na Miami University, onde dirige o Center For Education and Cultural Studies da universidade. Junto com Peter McLaren, Joe Kincheloe e Shirely Steinberg se ocupa da integração entre os Estudos Culturais e os estudos sobre a Educação. 
da política. Os autores antes citados coletaram resultados de alguns estudos que testemunham o rápido aumento do hiato que separa a opinião pública dos acontecimentos centrais da vida política. Logo após a invasão do Iraque, o New York Times publicou os resultados de uma sondagem em que $42 \%$ dos leitores americanos acreditavam que Saddam Hussein fosse diretamente responsável pelos ataques do Onze de Setembro ao World Trade Center e ao Pentágono. A CBS publicou resultados de outra enquete em que 55\% dos americanos acreditavam que Saddam Hussein apoiava a organização terrorista Al Qaeda. [...] Na verdade, nenhuma dessas crenças tinha base, já que não existia nenhuma prova que confirmasse, mesmo que vagamente, essas afirmações. Uma enquete conduzida pelo Washington Post pouco antes do segundo aniversário da tragédia do I I de Setembro, indicava que 70\% dos americanos continuavam a crer que o Iraque estivesse diretamente envolvido na organização dos ataques.

Nesse cenário de ignorância, é fácil sentir-se perdido e sem esperança, e é ainda mais fácil sentir-se perdido e privado de esperança quando não se tem capacidade de compreender aquilo que acontece. Como sublinhava Pierre Bourdieu, quem não tem uma visão mais acabada do presente não poderia sonhar controlar o futuro, e a maior parte dos americanos deve ter uma visão confusa do presente [...].

A ignorância leva à paralisia da vontade. Quem não sabe o que guarda no depósito, não tem como calcular os riscos.

Para a autoridade, intolerante em relação às proibições impostas pelos detentores do poder através de uma democracia "elástica e flutuante", essa impotência, induzida pela ignorância do eleitorado, bem como a desconfiança geral na eficácia do dissenso e a oposição ao envolvimento político, são fontes necessárias e bem-vindas de capital político: a dominação através da ignorância e da incerteza deliberadamente cultivadas é mais aceitável e menos cansativa do que o princípio baseado na discussão atenta dos acontecimentos e no esforço demorado de estabelecer a verdade dos fatos e os modos menos arriscados de proceder. A ignorância política entrançada com a inatividade fica ao alcance da mão cada vez que é sufocada a voz da democracia ou as suas mãos ficam atadas.

É preciso uma educação permanente para dar a nós mesmos a possibilidade de escolher. Mas temos ainda mais necessidade de salvar as condições que tornam as escolhas possíveis e ao nosso alcance. 


\section{REFERÊNCIAS BIBLIOGRÁFICAS}

BAUMAN, Z. Globalização: as consequências humanas. Rio de Janeiro: Jorge Zahar, 1999. . Em busca da política. Rio de Janeiro: Jorge Zahar, 2000.

. Modernidade líquida. Rio de Janeiro, 2001.

La Società individualizzata. Bologna: II Mulino, 2002.

Vida para consumo: a transformação das pessoas em mercadoria. Rio de Janeiro: Jorge Zahar, 2008.

Vidas desperdiçadas. Rio de Janeiro: Jorge Zahar, 2005.

BATESON, G. Verso un'ecologia della mente. Milano: Adelphi, 1976.

BOLTANSKI, L.; CHIAPELLO, È. Le Nouvel esprit du capitalism. Parigi: Gallimard, 1999.

BOURDIEU, P. Contre feux: propos pour server à la résistence contre l'invasion neoliberale. Paris: Raisons d'Agir, 1988.

CALVINO, I. As Cidades invisíveis. São Paulo: Companhia das Letras, 1990. [Trad.: Diogo Mainardes]

COMISSÃO EUROPEIA. Making a European area of lifebong learning a reality. Brussels, 2 I nov.2001. (Communication)

FOMBRUN, C. J.; TICHY, N. M.; DEVANA, M. A. (eds.) Strategic human resources management. New york: John Wiley \& Sons, 1984.

GIROUX, H. A.; GIROUX, S. S. Take back higer education: toward a democratic common. Tikkun, v. 18, n.6, p.28-32, nov./dec. 2003.

JAEGER, W. Paidea: Die Formung des griechischen Menschen. Berlin: Walter de Gruyter, 1958

MOILANEN, R. IIRD and learning: for whose well being? LLinE, n. I, p.34-39, 2004.

MYERS, E. D. Education in the perspective of history. New York: Harper, 1960.

RYCHER, D. S. Lifelong learning: but learning for what? LLiNe, n. I , p.26-33, 2004.

SORESSI, B. Ralph Valdo Emerson: il pensiero e la solitudine. Roma: Armando, 2004.

THOMAS, L. Editorial: Learning from different institutional and national experiences. Widening Participation and Lifelong Learning, Staffordshire, v.6, n. I, apr. 2004. Disponível em: www. staffs.ac.uk.journal/volume6(I )editor.htm. Acesso em: abr.2009. 
WOJCIECHOWSKI, J. Studia podyplomowe. Forum Akademickie, n.5, 2004. Disponível em: www.forumakad.pl/archiwum/2004/05// 0-agora-studia_podyplomowe.htm 2004. Acesso em: abr.2009.

Recebido em: maio 2008

Aprovado para publicação em: junho 2008 